\title{
Research on the Negative Transfer Effect of Guangxi Dialects on English Phonetic Learning
}

\author{
Miaomiao Xin, Jing Yang, Yanxia Zheng, Yusheng Zheng, Haizhen Zhao* \\ School of Foreign Studies, Guilin University of Electronic Technology, Guilin, Guangxi, 541004, China \\ *Corresponding author: Email: 7629332@qq.com
}

\begin{abstract}
This paper investigates the negative transfer effect of Guangxi dialects on English phonetic acquisition of college students in Guangxi. The study adopts the method of comparative analysis by recording the English pronunciation of college students from Guangxi Baihua, Zhuang, and Guiliu dialects. The English phonetic symbols influenced by Guangxi Baihua, Zhuanghua, and Guiliu dialects are found after comparison and analysis. The results of the study show that Guangxi Baihua, Zhuang and Guiliu dialects have a negative transfer effect on English phonetic acquisition of college students in Guangxi, which affects the accuracy of their pronunciation. Finally, this study proposes measures to overcome the negative transfer effect of dialects based on the analysis.
\end{abstract}

Keywords: Guangxi dialects, English, negative transfer

\section{INTRODUCTION}

Linguist A.C. Gimson argues that it is sufficient to master only $50 \%$ to $90 \%$ of grammar and $10 \%$ of vocabulary in a language, but it is necessary to master $100 \%$ of phonology. This shows the importance of phonology for language learning. However, second language learners are easily influenced by their native language in phonological learning. This phenomenon is known as language transfer. Odlin defines language transfer as the effect of similarities and differences between the target language and any other language that has been acquired (or not fully acquired) [1]. There are two types of language transfer: positive transfer and negative transfer. Positive transfer refers to positive effects of the first language in facilitating or accelerating the learning of the second language; negative transfer refers to negative effects of the first language in hindering or interfering with the learning of the second language.

The phenomenon of language transfer of Chinese on English phonology has been studied by scholars for quite a long time. However, the research on the negative transfer of Guangxi dialects on English phonetics is relatively weak. A considerable number of students in the university where the authors work come from Guangxi. And their phonetic learning is influenced by Mandarin and the dialects they have spoken since childhood. For example, when encountering unfamiliar sounds they tend to substitute them with similar ones in Mandarin or their dialects. Therefore, over time the negative influence of their native language will penetrate into English phonological learning. This validates the study of Le and Lin who found that any contact between two languages will influence each other and this contact and influence will inevitably lead to different biases or errors in the learning and use of the second language [2]. In addition, they found that the influence of Mandarin and dialects in students' English phonological learning is often mixed together. However, there is no relevant study that specifically analyzes and identifies the negative transfer of dialects and Mandarin on English phonological acquisition. Therefore, this study is of practical significance since it will not only enrich the scope of research on language transfer but provide specific help in improving English phonological learning of Guangxi students.

In this paper, the English pronunciation of some Guangxi students was recorded, analyzed and compared with the method of comparative analysis in order to reflect the influence of Guangxi dialects on phonological learning more intuitively. The English phonetics mentioned in this paper refers to British pronunciation and American pronunciation. And Guangxi dialects particularly refer to the common dialects of Baihua, Zhuang and Guiliu.

\section{RELATED STUDIES}

The current studies on language transfer are as follows.

\subsection{Current Studies on the Negative Transfer in Pronunciation at Home and Abroad}

Foreign scholars have conducted a large number of studies on language transfer including phonological transfer. Some current studies are as follows. Hyesun Cho examined the acoustic characteristics of cork fricatives and fricatives of Korean learners [3]; Barkana et al investigated the similarities and differences between the spectral and time-domain characteristics of vowel production in English words spoken by native speakers of 
Mandarin, Hindi, and American English [4]. Most foreign scholars studied the influence of speakers' native language on the phonological learning of a foreign language through a comparative approach. Therefore, the findings of this study will not only promote the development of phonological research, but also provide important references for the study of negative transfer of Chinese on English learning.

With the growing influence of the theory of language transfer and the need for more theoretical support for the development of phonological instruction, more and more Chinese scholars are engaged in English phonological research and have achieved fruitful results. Yang and Nie studied the negative transfer effect of Hakka dialect on English phonological learning [5]; Chen studied the negative transfer effect of Minnan dialect on English phonological learning [6]; Huang and Zhu studied the negative transfer effect of dialect on English phonological learning [7]. From the above studies, we can see that the domestic research on negative transfer of native language mainly focuses on the negative transfer effect of dialects on English phonological learning. However, there are very few studies on the negative transfer of Guangxi dialects on English phonological learning.

\subsection{Current Research on the Negative Transfer Effect of Guangxi Dialects on English Phonetic Acquisition}

There are few studies on the negative transfer effect of Guangxi dialects on English phonetic learning. The research mainly focuses on the following aspects. Zhao dealt with the negative transfer effect when studying the effect of Guangxi dialect on English phonetic acquisition of college students from minority groups [8]. And suggestions are provided to overcome the negative transfer from the perspectives of teachers and students respectively. However, the suggestion are not specific and creative enough; $\mathrm{Wu}$ and Chen distinguished between positive and negative transfer in their study of the influence of Cantonese on English phonological acquisition among college students of ethnic minority [9]. The study recorded the pronunciation of the subjects with a tape recorder and then processed them with the software called Praat on the basis of manual discrimination. However, the software is complicated to operate and is only suitable for scholars to serve as an aid for research instead of daily use. Besides, the research failed to reflect the results of the recordings in a direct and clear way. Yang et al studied the adverse effects of Guangxi Baihua, Zhuang dialect, and Guilu dialect on English phonological learning, but ignored the interference of Mandarin [10]. The method of recording assessment adopted in the research does not explicitly reflect the recording results. It can be seen from the above studies that the research on negative transfer of Guangxi dialects has room for improvement both in terms of research methods and content.

\section{RESEARCH METHOD}

\subsection{Research Questions}

This research is aimed to answer the following questions: (1) What are the phonological differences between English and Guangxi Baihua, Zhuang, Guiliu and Mandarin?

(2) What are the phonemes that are affected by the negative transfer of Guangxi Baihua, Zhuang and Guiliu?

(3) How to effectively reduce the negative transfer effect of Guangxi Baihua, Zhuang and Guiliu?

\subsection{Research Subjects}

In this paper, 45 college students from Guangxi are randomly selected from departments or schools of Guilin University of Electronic Technology. Their English pronunciation was recorded and assessed. Among them, 15 students speak the dialect of Guangxi Baihua, 15 students speak the dialect of Zhuang and 15 students Guiliu.

\subsection{Research Method}

The study employs the method of comparative analysis to record the English pronunciation of the subjects with the help of Eudic, an English learning application to record and assess the pronunciation of speakers. Then analysis is made about the negative transfer effect of Guangxi Baihua, Zhuang and Guiliu on English phonetic learning. Besides the study analyzed the phonetic differences between English and Guangxi Bahua, Zhuang and Guiliu.

Phonetic symbols are the foundation of English phonetic learning. Therefore, learners' mastery of phonetic symbols directly affects the accuracy of their pronunciation. The Eudic provides accurate feedback on the assessment of British and American pronunciation down to the syllable level. And it can tell whether the pronunciation of relevant phonemes is correct or not. Therefore 26 words are chosen by this research for subjects to read, record and compare. These words are pig, boy, deaf, for, she, some, thank, children, cats, like, where, no, yellow, poor, tall, goods, vase, treasure, zoo, they, job, here, write, mouth, sing, and earth. These words cover all the English phonetic symbols. Finally, the paper analyzed the data based on the recording.

\section{RESEARCH RESULTS AND ANALYSIS}

\subsection{Research Data}

The data collected in the research are presented in the following tables. 


\subsubsection{Assessment results of students whose dialect is Guangxi Baihua}

The data show a total of 31 phonetic symbols with incorrect pronunciation. The error rate is shown in Table 1 from the highest to the lowest.

Table 1 Error rate of students speaking Guangxi Baihua

\begin{tabular}{|c|c|c|c|c|c|c|c|c|c|c|}
\hline $\begin{array}{l}\text { Phonetic } \\
\text { symbols }\end{array}$ & $|z|$ & $\begin{array}{l}/ a / \\
/ \mathrm{y} /\end{array}$ & /i/ & $\begin{array}{l}\text { /v/ } \\
\text { /e/ } \\
\text { /a:/ }\end{array}$ & $/ \theta /$ & /f/ & $\begin{array}{c}/ \mathrm{p} / / \mathrm{w} / \\
/ \mathrm{m} /\end{array}$ & $\begin{array}{l}/ \mathrm{dr} / 、 / \mathfrak{x} / \\
/ \mathrm{k} / 、 \quad / \mathrm{dz} / \\
/ \mathrm{tr} / 、 / \mathrm{b} / \\
/ \mathrm{t} / 、 / 3 / \\
/ \mathrm{n} /, \quad / \Lambda /\end{array}$ & $\begin{array}{l}\text { /l/ } \\
\text { /r/ } \\
\text { /au/ } \\
\text { /0: / }\end{array}$ & $\begin{array}{l}/ \curvearrowright: / \\
/ ठ / \\
\text { /əu/ } \\
\text { /g/ } \\
\text { /s/ }\end{array}$ \\
\hline Error rate & $80 \%$ & $66.67 \%$ & $60 \%$ & $53.33 \%$ & $46.67 \%$ & $33.33 \%$ & $26.67 \%$ & $20 \%$ & $13.33 \%$ & $6.67 \%$ \\
\hline
\end{tabular}

According to the data there are 39 phonetic symbols 4.1.2. Assessment results of students whose showing incorrect pronunciation and the error rate from dialect is Guangxi Zhuang the highest to the lowest is shown in Table 2.

Table 2 Error rate of students speaking Guangxi Zhuang

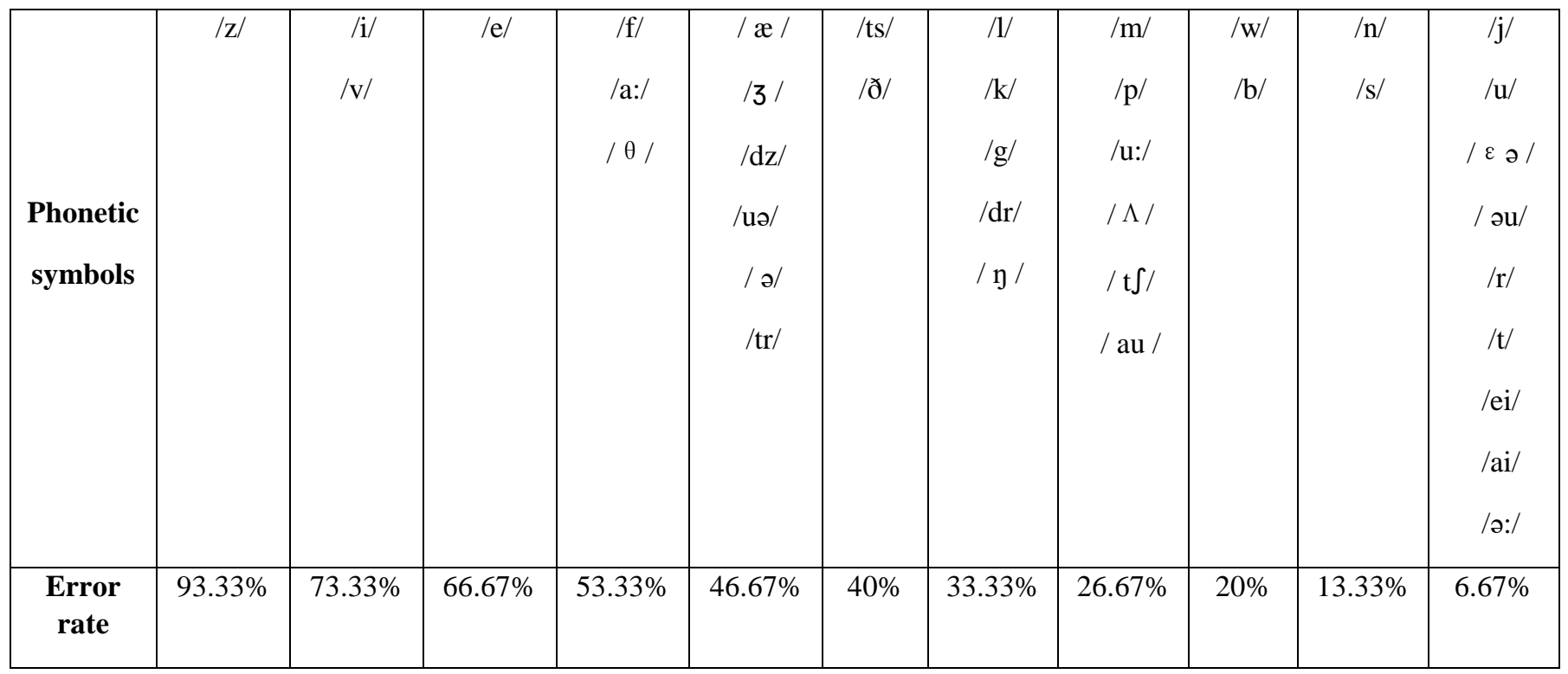

\subsubsection{Assessment results of students whose dialect is Guangxi Guiliu}

There are 40 phonetic symbols showing incorrect pronunciation and the error rate from the highest to the lowest is shown in Table 3. 
Table 3 Error rate of students speaking Guangxi Guiliu

\begin{tabular}{|c|c|c|c|c|c|c|c|}
\hline $\begin{array}{l}\text { Phonetic } \\
\text { symbols }\end{array}$ & $|z|$ & $/ \partial /$ & /e/ & $\begin{array}{l}/ \theta / \\
/ \mathrm{i} / \\
/ \mathrm{au} /\end{array}$ & $\begin{array}{l}/ \mathrm{dz} / \\
/ \mathrm{f} /\end{array}$ & $\begin{array}{l}\text { /dr/ } \\
\text { /uə/ } \\
\text { /v/ } \\
\text { /y/ }\end{array}$ & $\begin{array}{l}\text { /a:/ } \\
/ \Lambda / \\
/ 3 /\end{array}$ \\
\hline Error rate & $100 \%$ & $86.67 \%$ & $80 \%$ & $73.33 \%$ & $60 \%$ & $53.33 \%$ & $46.67 \%$ \\
\hline $\begin{array}{l}\text { Phonetic } \\
\text { symbols }\end{array}$ & $\begin{array}{l}/ \mathrm{b} / \\
/ \mathrm{k} /\end{array}$ & $\begin{array}{l}/ \mathrm{m} / \\
/ \mathrm{s} / \\
/ \mathrm{g} /\end{array}$ & $\begin{array}{r}æ æ / 、 / \mathrm{u} / \\
/ \mathrm{p} / 、 / \mathrm{s} / \\
/ \mathrm{n} / 、 / \mathrm{ts} / \\
/ \mathrm{l} /\end{array}$ & $\begin{array}{l}/ \mathrm{d} / \\
/ \mathrm{t} / \\
/ \mathrm{u}: /\end{array}$ & $\begin{array}{l}/ \mathrm{tr} / \\
/ \mathrm{j} /\end{array}$ & $\begin{array}{l}\text { /i:/ /ea/ } \\
\text { /w/, /h/ } \\
\text { /r/, /iə/ } \\
\text { /d3/、/ai/ }\end{array}$ & \\
\hline Error rate & $40 \%$ & $33.33 \%$ & $26.67 \%$ & $20 \%$ & $13.33 \%$ & $6.67 \%$ & \\
\hline
\end{tabular}

\subsection{Data Analysis}

Since the subjects speak both Mandarin and dialects, their English pronunciation will be influenced by dialects as well as Mandarin. It was found that there are direct and indirect effects of dialects on English phonology. The direct effect is that the learners directly substitute the similar pronunciation in the dialects when they encounter unfamiliar sounds. And the indirect effect lies in the fact that the pronunciation of their dialects will cause negative transfer on Mandarin and then indirectly affect the English pronunciation. When students encounter unfamiliar pronunciation in English, they tend to replace it with similar one in Mandarin. But this is a similar pronunciation in non-standard Mandarin, which is also a similar pronunciation in dialect in the final analysis. Therefore, we also need to compare English, Mandarin, and Guangxi dialect. The results of the comparison are as follows.

\subsubsection{Comparative analysis of Mandarin and English in phonetics}

Pinyin and phonetic symbols are the basis for phonetic learning of Mandarin and English respectively. So the paper first analyzed the similar sounds of pinyin and phonetic symbols as follows.

Table 4 Similar sounds in English and Pinyin

\begin{tabular}{|c|c|c|c|c|c|c|c|c|c|}
\hline English & $\begin{array}{l}/ \mathrm{i}: / \\
\text { / i / }\end{array}$ & $\begin{array}{l}\text { /a:/ } \\
\text { / } /\end{array}$ & $\begin{array}{l}\text { /0: / } \\
10 /\end{array}$ & $\begin{array}{l}\text { /u: / } \\
\text { /u / }\end{array}$ & $\begin{array}{l}/ \mathrm{a} / / \\
/ \mathrm{\partial} /\end{array}$ & /ei/ & /ai/ & /ou/ & \\
\hline Pinyin & $\mathrm{i}$ & $\mathrm{a}$ & o & $\mathrm{u}$ & e & ei & ai & ou & \\
\hline English & /au/ & $/ \mathrm{p} /$ & $/ \mathrm{b} /$ & $/ \mathrm{t} /$ & $/ \mathrm{d} /$ & $/ \mathrm{k} /$ & $/ \mathrm{h} /$ & $/ \mathrm{f} /$ & \\
\hline Pinyin & ao & $\mathrm{p}$ & $\mathrm{b}$ & $\mathrm{t}$ & $\mathrm{d}$ & $\mathrm{k}$ & $\mathrm{h}$ & $f$ & \\
\hline
\end{tabular}


diphthongs that are composed of two unit sounds with similar sounds in pinyin (shown in the table above). Therefore, the pronunciation of these diphthongs will also be influenced by pinyin. In addition, $/ \theta /, / ð /$ and pinyin $[\mathrm{s}]$, [ts(z)] are similar in terms of phonological system. In summary, except for the phonetic symbols / e/, /æ/, /v/, /z/, $/ \mathrm{tr} /, / \mathrm{dr} /$, all the other phonetic symbols have their pinyin counterparts, which means that learners will be influenced by the transfer effect of Mandarin when learning the remaining 42 phonetic symbols.

\subsubsection{Comparative analysis of Guangxi Baihua with Mandarin and English in phonetics}

Subjects whose dialect is Guangxi Baihua often reveal the following phonetic phenomena when speaking Mandarin.

(1) They cannot distinguish Pinyin $n$ with phonetic symbol $/ \mathrm{n} /$, which indirectly affects the pronunciation of $/ \mathrm{n} /$ and $/ \mathrm{y} /$. According to the data, nearly $66.67 \%$ of the respondents mispronounced $/ \mathrm{y} /$, indicating that Guangxi Baihua has a negative transfer effect on this phonetic symbol.

(2) There is no pinyin $e$ in their dialects. As pinyin $e$ is similar to the phonetic symbols /ə:/ and /ə/, the mispronunciation of $/ \mathrm{\partial}: /$ and $/ \mathrm{a} /$ is not caused by the negative transfer of the dialect of Guangxi Baihua.

(3) They cannot distinguish long sounds with short sounds. Among the examples are $/ \mathrm{i}: /$ and $/ \mathrm{i} /$, /a:/ and $/ \Lambda /, / \mathrm{o}: /$ and /o/, and /u:/ and /u/. However only / i /, /a:/, / / /, and /o:/ are mispronounced, which indicates that Guangxi Baihua has negative transfer effect on the four phonetic symbols mentioned.

(4) They cannot distinguish Pinyin $r$ with $n$, which indirectly affects the pronunciation of phonetic symbols $/ \mathrm{r} /$ and $/ \mathrm{n} /$. Phonetic symbol $/ 3 /$ is also affected as a result because it is similar to the pronunciation of pinyin $r$. The data show that all the three phonetic symbols are mispronounced by some subjects, which means that Guangxi Baihua has a negative transfer effect on these three phonetic symbols.

(5) They cannot distinguish Pinyin $z h, s h$, ch from pinyin $z$, $s$, and $c$. The phonetic symbols similar to these pinyin are $/ \mathrm{d} z /, / \mathrm{J} /, / \mathrm{t} \mathrm{J} /, / \mathrm{dz} /, / \mathrm{s} /, / \theta /$, and $/ \mathrm{ts} /$. Therefore, these phonetic symbols are affected in an indirect way. However, data show that only $/ \theta /, / \mathrm{dz} /$, and $/ \mathrm{s} /$ are mispronounced. That means that Guangxi Baihua has a negative transfer effect on the three phonetic symbols.

(6) They cannot tell the distinction between pinyin $a o$ and $o u$, which will indirectly affect the phonetic symbols /au/ and $/ \mathrm{ou} / \mathrm{similar}$ to pinyin $a o$ and $o u$ in pronunciation. According to the data, both phonetic symbols are mispronounced by certain subjects, indicating that Guangxi Baihua has a negative transfer effect on the two phonetic symbols.

(7) The pronunciation of phonetic symbols $/ \mathrm{w} /$ and $/ \mathrm{v} /$ is indirectly affected by the lack of distinction between pinyin $\mathrm{w}$ and phonetic symbol $/ \mathrm{v} /$. According to the data, both phonetic symbols are mispronounced by some subjects, indicating that Guangxi Baihua has a negative transfer effect on these two phonetic symbols.

In summary, the phonemes affected by the negative transfer effect of Guangxi Baihua are /n/, /y/, / i /, /a:/, / / , $/ \mathrm{s} / /, / \mathrm{r} /, / \mathrm{z} /, / \theta /, / \mathrm{dz} /, / \mathrm{s} /, / \mathrm{w} /$ and $/ \mathrm{v} /$.

\subsubsection{Comparative analysis of Zhuang, Mandarin and English in phonetics}

Subjects whose dialect is Zhuang show the following phonetic phenomena when speaking Mandarin.

(1) They cannot distinguish between $b$ and $p$ in pinyin, which indirectly affects the mastery of phonetic symbols $/ \mathrm{b} /$ and $/ \mathrm{p} /$. According to the data the two symbols are mispronounced by the subjects. This proved the negative transfer effect of Zhuang dialect on the two phonetic symbols mentioned above.

(2) The mispronunciation of $d$ and $t$ in Pinyin indirectly affects the mastery of phonetic symbols /d/ and /t/. However, data show only /t/ was mispronounced, indicating that Zhuang dialect has a negative transfer effect on $/ \mathrm{t} /$.

(3) The mispronunciation of $g$ and $k$ in Pinyin indirectly affects subjects' pronunciation of phonetic symbols /g/ and $/ \mathrm{k} /$. According to the data, both symbols are mispronounced, which indicates that Zhuang dialect has a negative transfer effect on the two phonetic symbols.

(4) The mispronunciation of $w$ and $h$ in Pinyin indirectly affects the pronunciation of phonetic symbols $/ \mathrm{w} /$ and $/ \mathrm{h} /$. However, the data show only /w/ was mispronounced. That means that Zhuang dialect has a negative transfer effect on $/ \mathrm{w} /$.

(5) Subjects' inability of distinguishing between $w$ in Pinyin and the phonetic symbol / $/$ / indirectly affects the pronunciation of the phonetic symbols $/ \mathrm{w} /$ and $/ \mathrm{v} /$. According to the data, both $/ \mathrm{w} /$ and $/ \mathrm{v} /$ are mispronounced, indicating that Zhuang dialect has a negative transfer effect on the two two phonetic symbols.

(6) Subjects' inability of distinguishing between $s, c$ and $z$, $s h, c h$, and $z h, s$ and $s h, c$ and $c h, z$ and $z h$ indirectly affected the phonetic symbols $/ \theta /, / \mathrm{s} /, / \mathrm{ts} /, / \mathrm{dz} /, / \mathrm{J} /, / \mathrm{t} /$, and $/ \mathrm{d}_{3} /$ that are similar to the pronunciation of the above pinyin. According to the data, only $/ \theta /, / \mathrm{s} /, / \mathrm{ts} /, / \mathrm{dz} /$, and $/ \mathrm{t} / /$ are mispronounced, indicating that Zhuang dialect has a negative transfer effect on these five phonetic symbols. In summary, there are no aspirated phonemes in Zhuang dialect. The phonemes affected by negative transfer in Zhuang dialect are $/ \mathrm{b} /, / \mathrm{p} /, / \mathrm{t} /, / \mathrm{w} /, / \mathrm{g} /, / \mathrm{k} /, / \mathrm{v} /, / \mathrm{s} /, / \mathrm{ts} /$, /dz/, /J/, /t $\mathrm{f} /$ and $/ \mathrm{d} z /$.

\subsubsection{Comparative analysis of Guiliu, Mandarin and English in phonetics}

Some phonological phenomena occurred when subjects whose dialect is Guiliu as follows.

(1) Pinyin $z h$, sh, and $c h$ are not distinguished from pinyin $z$, $s$, and $c$, respectively. These pinyin are similar to 
phonetic symbols /dz/, / $/, / \mathrm{t} / /, / \mathrm{dz} /, / \mathrm{s} /, / \theta /$, and $/ \mathrm{ts} /$. Therefore, this indirectly affected their mastery of these phonetic symbols. However, according to the data, the phonetic symbols with wrong pronunciation are only $/ \theta /$, $/ \mathrm{ts} /, / \mathrm{d} z /, / \mathrm{s} /$, and $/ \mathrm{dz} /$. So Guiliu dialect has a negative transfer effect on these five phonetic symbols.

(2) Pinyin $r$ and $l$ are easily confused by these subjects, which indirectly affected the mastery of phonetic symbols $/ \mathrm{r} /$ and $/ \mathrm{l} /$ similar to pinyin $r$ and $l$. According to the data, both phonetic symbols are mispronounced by the subjects, indicating that Guiliu dialect has a negative transfer effect on these two phonetic symbols.

(3) Pinyin $a i$ and an are not pronounced properly. Pinyin $a i$ is similar to the phonetic symbol /ai/ which is easily confused with the phonetic symbol /e/. According to the data, both phonetic symbols /ai / and /e/ are mispronounced. As many as $80 \%$ subjects mispronounced /e/, indicating that Guiliu dialect has a negative transfer effect on these two phonetic symbols.

(4) Pinyin $w$ and phonetic symbol /v/ are confused by subjects, which indirectly affected the pronunciation of phonetic symbols $/ \mathrm{w} /$ and $/ \mathrm{v} /$. According to the data, both phonetic symbols were mispronounced by the subjects and most of them mispronounced $/ \mathrm{v} /$ as $/ \mathrm{w} /$. This indicates that Guiliu dialect has a negative transfer effect on these two phonetic symbols.

In summary, the phonemes affected by negative transfer in Guiliu dialect are: / $/$ /, /ts/, /dz/, /s/, /dz/, /r/, /l/, /ai/, /e/, /w/ and $/ \mathrm{v} /$.

\section{SUGGESTIONS TO REDUCE THE NEGATIVE TRANSFER EFFECT}

Based on the above analysis, this paper provides the following suggestions.

(1) From the perspective of students, the first step for them is to identify the phonetic symbols that are affected by negative transfer. Then practice reading along to master the correct pronunciation.

(2) From the perspective of teachers, English teachers should give full play to their instructional role by facilitating teaching equipment, improving teaching methods, etc.

(3) From the perspective of schools, more English phonetics-related contests such as English speech contests should be held to provide more learning platforms for students and stimulate their learning interests.

\section{CONCLUSION}

In this paper, some college students from Guangxi dialects area were selected and their English pronunciation were measured and analyzed with the help of Eudic to find out the influence of dialects on the learning of English phonetics. The results of the study showed that the dialects have both direct and indirect effect on English phonetics learning. And there are more indirect effects. For example, the majority of students mispronounced the phonetic symbol / $\mathrm{z} /$ because there is not a similar sound in Guangxi Baihua, Zhuang and Guiliu. Finally, there is still room for research on dialects and English phonology, such as the negative effect of dialects on English intonation.

\section{ACKNOWLEDGMENT}

This work was supported by Guangxi Innovation and Entrepreneurship Training Program for College Students (201910595240), the Teaching Reform Project of Guangxi Higher Education (2020JGZ117), the Teaching Reform Project of Guilin University of Electronic Technology (JGB202015) and Planning Project of Guangxi Education Sciences (2019ZJY111)

\section{REFERENCES}

[1] Terence Odlin, Language Transfer: Cross-linguistic Influence in Language Learning. Cambridge University Press, 1989.

[2] Le. Meiyun, Lin Dexiang, Analysis of students' English pronunciation errors in various dialects in China: Comparative phonetic studies between Chinese and English, Foreign Language Research, Vol. 41, 1994, pp. 55-60.

[3] Hyesun Cho, An acoustical analysis of English postalveolar fricatives and affricates produced by Korean and English speakers. Studies in Phonetics, Phonology and Morphology, Vol. 23, 2017, pp. 293-342.

[4] D. B.Buket, P. Aarchi, Analysis of vowel production in Mandarin/Hindi/American-accented English accent recognition systems. Applied Acoustics, Vol.162, 2020.

[5] Yang Qirui, Nie Hua, Research on the negative transfer of Hakka dialect on English phonetic learning and strategies, Overseas English, Vol, 15, 2020, pp. $252-253$

[6] Chen Huiqun, Analysis of the negative transfer of Minnan dialect on English phonetics and strategies, Tests and Research, Vol. 15, 2020, pp. 64-65.

[7] Huang Lingqing, Zhu Siming, A study on the negative transfer effect of dialect on English phonetic learning, Overseas English, Vol. 12, 2020, pp. 61-62.

[8] Zhao Xiaoli, Influence of Guangxi dialect on English phonetic acquisition of college students from minority ethnic groups and strategies, Comparative Study of Cultural Innovation, Vol. 2, 2018, pp. 85, 89. 
[9] Wu Xianze, Chen Hui, Influence of Cantonese in Guangxi border on English Phonetic Acquisition of Ethnic Minority College Students and strategies,

Journal of Inner Mongolia Normal University:

Education Science Edition, Vol. 8, 2026, pp. 40-43.

[10] Yang Jingjie, Shu, Z, He, H, et al., Influence of Guangxi Dialects on English phonetics, Education Research, Vol. 1, 2018, pp. 10-12. 